\title{
A Design of E-Shaped Rectangular Fractal Antenna by using Line Feeding Technique
}

\author{
Ramandeep Kaur \\ M.Tech Scholar \\ Electronics and Communication \\ Engineering Deptt. \\ Amritsar College of Engineering \\ and Technology, Amritsar
}

\author{
Narinder Sharma \\ Associate Professor \\ Electronics and Communication \\ Engineering Deptt. \\ Amritsar College of Engineering \\ and Technology, Amritsar
}

\begin{abstract}
This paper presents a design of E-shaped rectangular fractal antenna and the excitation is provided by using the microstrip line feeding technique. FR4 glass epoxy is used as a substrate material with relative permittivity 4.4 , thickness $1.6 \mathrm{~mm}$ and the resonant frequency is taken as $3.2 \mathrm{GHz}$ for the designing of proposed antenna. The three iterations is designed and simulated by using HFSS V13 (High Frequency Structure Simulator Version 13) software. Antenna parameters such as return loss, VSWR, gain and bandwidth are simulated and observed. The simulated result shows that the designed antenna works on five different resonant frequencies where the return losses are below the acceptable level $-10 \mathrm{~dB}$. The designed antenna can be used for various wireless applications such as WLAN, long distance communications, space communication etc.
\end{abstract}

\section{Keywords}

HFSS, return loss, E-shaped, Fractal.

\section{INTRODUCTION}

A fractal antenna is an antenna that uses a fractal, self-similar design to maximize the length, or increase the perimeter (on inside sections or the outer structure), of material that can receive or transmit electromagnetic radiation within a given total surface area or volume. B. Mandelbort in 1975 defined the concept of fractal geometry and its iterative structure at different levels [3-9].

Such fractal antennas are also referred to as multilevel and space filling curves, but the key aspect lies in their repetition of a motif over two or more scale sizes or "iterations". For this reason, fractal antennas are very compact, multiband or wideband, and have useful applications in cellular telephone and microwave communications. [4]

Fractal geometry is used to reduce the size of patch antenna. The two properties of fractal antennas are space-filling and self-similarity [5-10]. It has been shown that the selfsimilarity properties of the fractal shapes can be successfully applied to the design of multiband fractal microstrip patch antenna. There are a number of fractal shapes like Sipernski Gasket, Minkowski, Hilbert curve and Koch curves [1]. Further it is analyzed that after a few iteration gain, bandwidth and other factors begin to decrease. A microstrip antenna consists of a metallic pattern on one side of a dielectric substrate and ground plane on the other side of the substrate. Microstrip antenna has disadvantages like low return loss, less bandwidth and low gain. So as to improve characteristics, fractal geometry has been applied [2].Fractal theories have become an innovative approach for designing wideband and multiband antennas [6]. The infrastructure of fractal antenna used for various wireless communication applications such as ISM, GPS, GSM, Bluetooth, RFID, WLAN, Wi-Fi, Wi-Max in the lower microwave frequency regions from $900 \mathrm{MHz}$ to $12 \mathrm{GHz}[7-8]$

\section{ANTENNA DESIGN}

The dimensions (length and width) of rectangular patch has been calculated by using the equation 1 to 5 and are found to be $21.92 \mathrm{~mm}$ and $28.52 \mathrm{~mm}$ respectively these dimensions are calculated by using resonant frequency of $3.2 \mathrm{GHz}$. The $0^{\text {th }}$ iteration of proposed antenna is shown in Figure 1 and the parametric values are shown in Table 1.

$$
\begin{aligned}
& w=\frac{C}{2 f o \sqrt{\frac{\varepsilon_{r}+1}{2}}} \\
& \varepsilon_{\text {reff }}=\frac{\varepsilon_{r}+1}{2}+\frac{\varepsilon_{r}-1}{2}\left[1+12 \frac{h}{w}\right]^{\frac{1}{2}}
\end{aligned}
$$

(2)

$$
\begin{aligned}
& L_{e f f}=\frac{C}{2 f o \sqrt{\varepsilon_{\text {reff }}}} \\
& \Delta L=0.412 h \frac{\left(\varepsilon_{\text {reff }}+0.3\right)\left(\frac{w}{h}+0.264\right)}{\left(\varepsilon_{\text {reff }}-0.258\right)\left(\frac{w}{h}+0.8\right)} \\
& L=L_{\text {eff }}+2 \Delta L
\end{aligned}
$$

Where,

$c=$ Velocity of light in free space.

$h=$ Substrate height.

$\varepsilon_{r}=$ Relative permittivity of the substrate.

$W=$ Width of rectangular patch.

$L=$ Length of rectangular patch.

$L_{\text {eff }}=$ Effective length .

$\varepsilon_{e f f}=$ Effective dielectric constant.

$f_{o=}$ Resonant frequency.

$\Delta L=$ Length extension.

The $1^{\text {st }}$ iteration of proposed antenna has been designed by introducing the E-shaped fractal slots at both sides of the width of rectangular patch as shown in Figure 2 by taking all the other dimensions are similar as in $0^{\text {th }}$ iteration of proposed 
antenna. The parametric values of E-shaped fractal slots are shown in Table 2

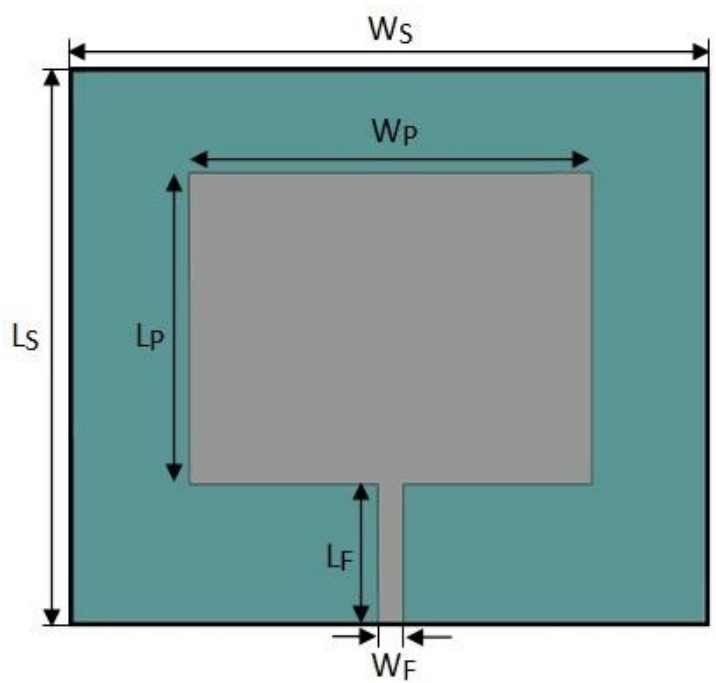

Figure 1: $0^{\text {th }}$ iteration of proposed fractal antenna

Table 1: Parametric values of $0^{\text {th }}$ iteration of proposed antenna

\begin{tabular}{|c|c|c|c|}
\hline S. No. & Parameters & Description & Values \\
\hline 1. & $\mathrm{~W}_{\mathrm{S}}$ & Width of Substrate & $45 \mathrm{~mm}$ \\
\hline 2. & $\mathrm{~L}_{\mathrm{S}}$ & Length of Substrate & $44.92 \mathrm{~mm}$ \\
\hline 3. & $\mathrm{~W}_{\mathrm{P}}$ & Width of Patch & $28.52 \mathrm{~mm}$ \\
\hline 4. & $\mathrm{~L}_{\mathrm{P}}$ & Length of Patch & $21.92 \mathrm{~mm}$ \\
\hline 5. & $\mathrm{~W}_{\mathrm{F}}$ & Width of Feed Line & $1.8 \mathrm{~mm}$ \\
\hline 6. & $\mathrm{~L}_{\mathrm{F}}$ & Length of Feed Line & $9.89 \mathrm{~mm}$ \\
\hline
\end{tabular}
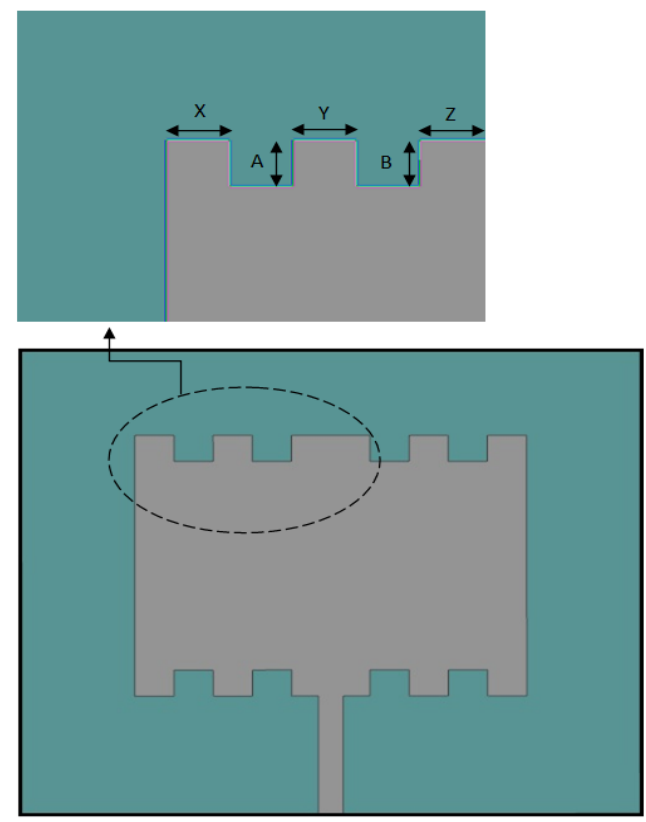

Figure 2: $1^{\text {st }}$ iteration of proposed fractal antenna
Table 2: Parametric values of E-shaped Fractal slots for $\mathbf{1}^{\text {st }}$ iteration

\begin{tabular}{|c|c|c|}
\hline S. No. & Parameters & Values \\
\hline 1. & $\mathrm{X}=\mathrm{Y}=\mathrm{Z}$ & $2.852 \mathrm{~mm}$ \\
\hline 2. & $\mathrm{~A}=\mathrm{B}$ & $2.192 \mathrm{~mm}$ \\
\hline
\end{tabular}

By taking the $1^{\text {st }}$ iteration as a base geometry, the fractal slots are further cut out from the E-shaped fractal slots to get the $2^{\text {nd }}$ iteration of the proposed fractal antenna as shown in Figure 3 and the parametric values for $2^{\text {nd }}$ iteration are shown in Table 3.

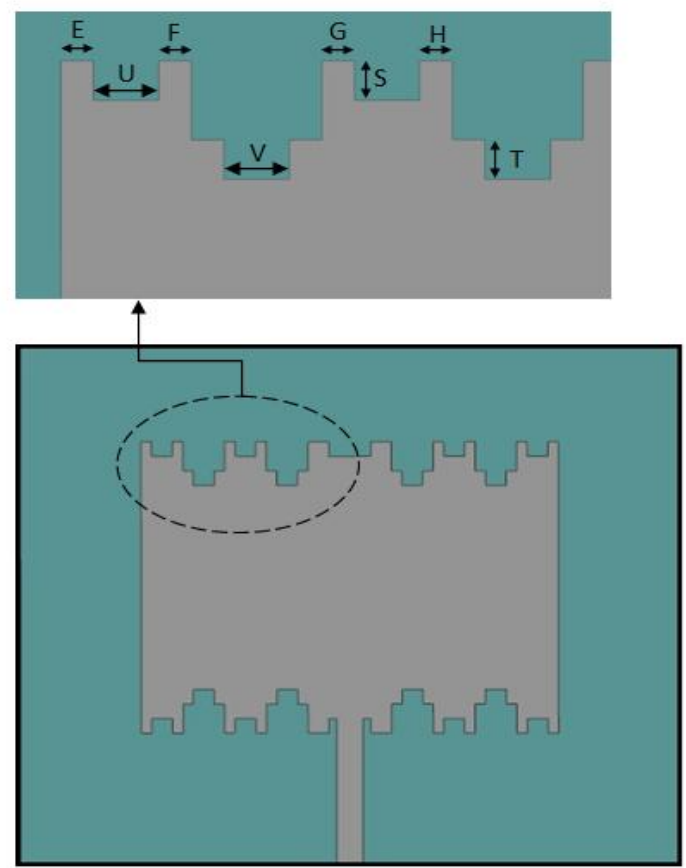

Figure 3: $2^{\text {nd }}$ iteration of proposed fractal antenna

Table 3: Parametric values of Fractal slots for $2^{\text {nd }}$ iteration

\begin{tabular}{|c|c|c|}
\hline S. No. & Parameters & Values \\
\hline 1. & $\mathrm{U}=\mathrm{V}$ & $1.426 \mathrm{~mm}$ \\
\hline 2. & $\mathrm{~S}=\mathrm{T}$ & $1.096 \mathrm{~mm}$ \\
\hline 3. & $\mathrm{E}=\mathrm{F}=\mathrm{G}=\mathrm{H}$ & $0.713 \mathrm{~mm}$ \\
\hline
\end{tabular}

\section{RESULT AND DISCUSSIONS}

\subsection{Return loss}

Figure 4, 5 and 6 shows the simulated return loss against frequency for the proposed E-shaped rectangular fractal antenna. It is clearly seen that on increasing iteration number the return loss and the resonant frequency bands increases. The acceptable value of return loss is less than $-10 \mathrm{~dB}$. The values of return loss at different frequencies for three iterations of proposed antenna are at the acceptable level and the values are shown in Table 4. 


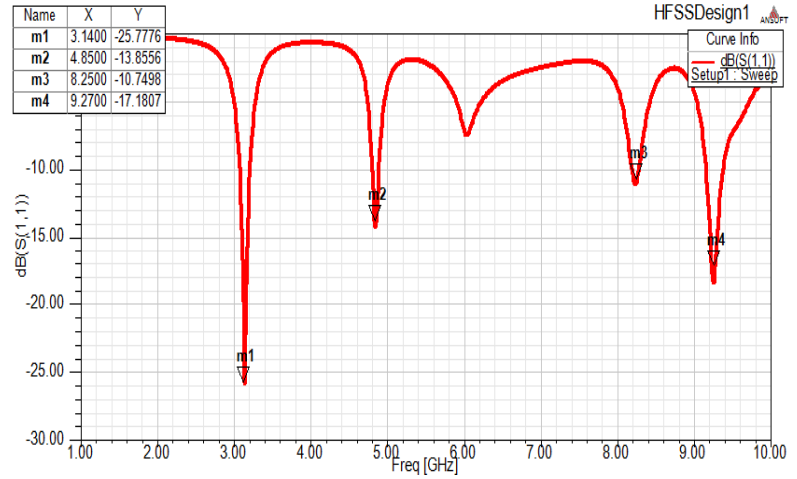

Figure 4: Return loss v/s frequency plot for $0^{\text {th }}$ iteration of proposed fractal antenna

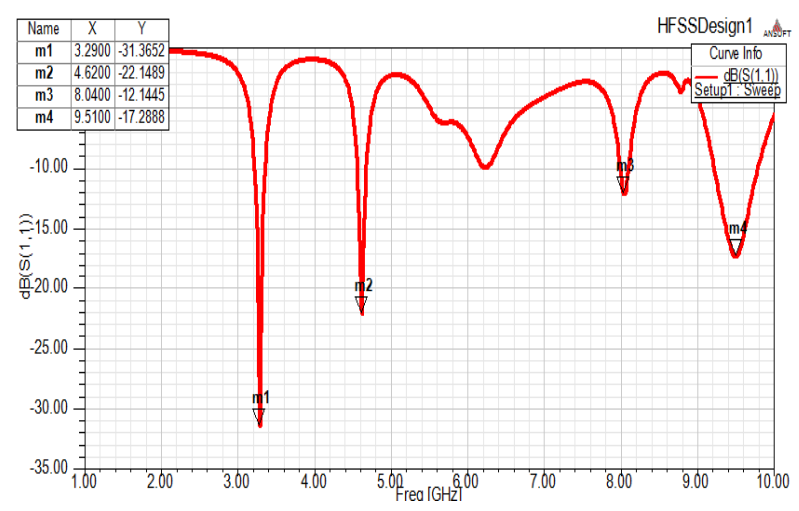

Figure 5: Return loss v/s frequency plot for $1^{\text {st }}$ iteration of proposed fractal antenna

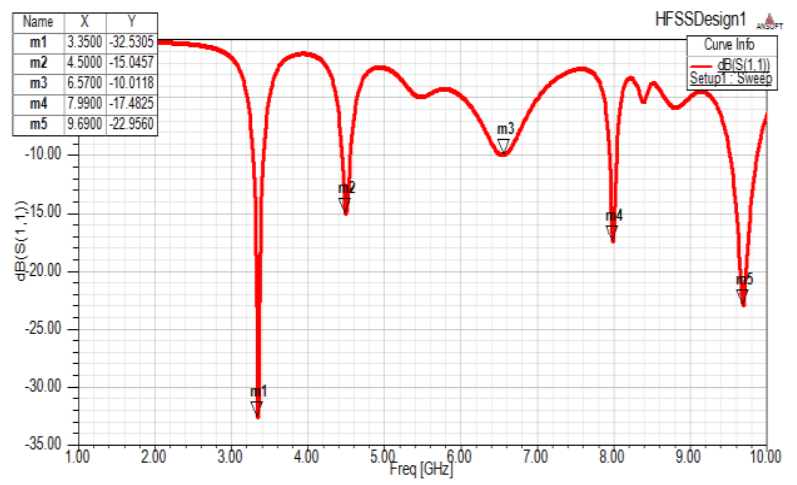

Figure 6: Return loss v/s frequency plot for $2^{\text {nd }}$ iteration of proposed fractal antenna

\subsection{Gain}

Gain is an important parameter of antenna it shows the efficiency and directional capabilities of antenna. The value of the gain should be positive for the antenna to work efficiently. The 3-D gain plots for the $2^{\text {nd }}$ iteration of proposed antenna at different resonant frequencies are shown in Figure 7, 8, 9, 10 and 11 and the values are shown in Table 4.
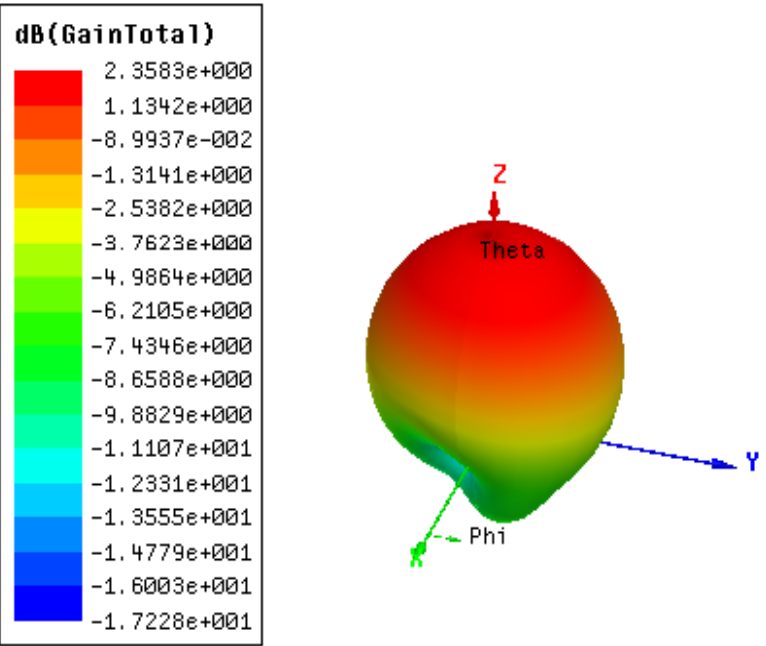

Figure 7: 3-D gain plot for $2^{\text {nd }}$ iteration of proposed fractal antenna at $3.35 \mathrm{GHz}$ frequency
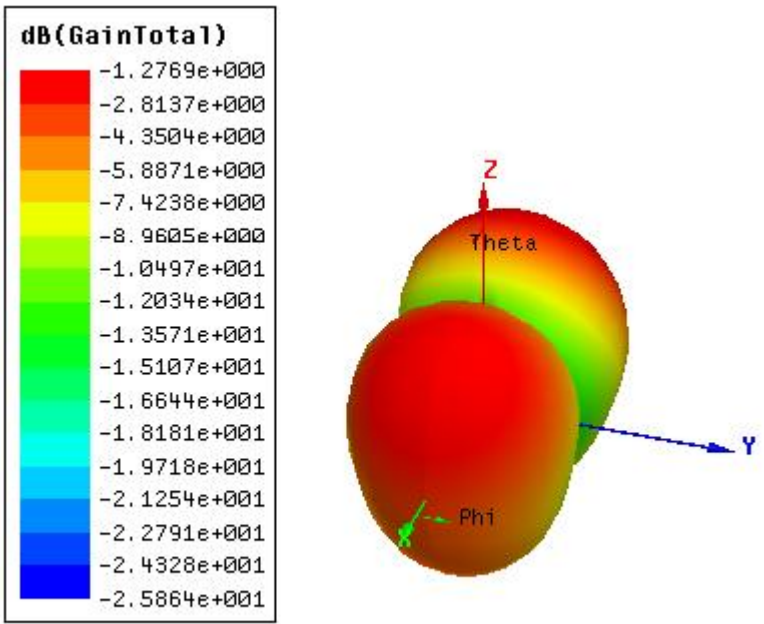

Figure 8: 3-D gain plot for $2^{\text {nd }}$ iteration of proposed fractal antenna at $4.5 \mathrm{GHz}$ frequency
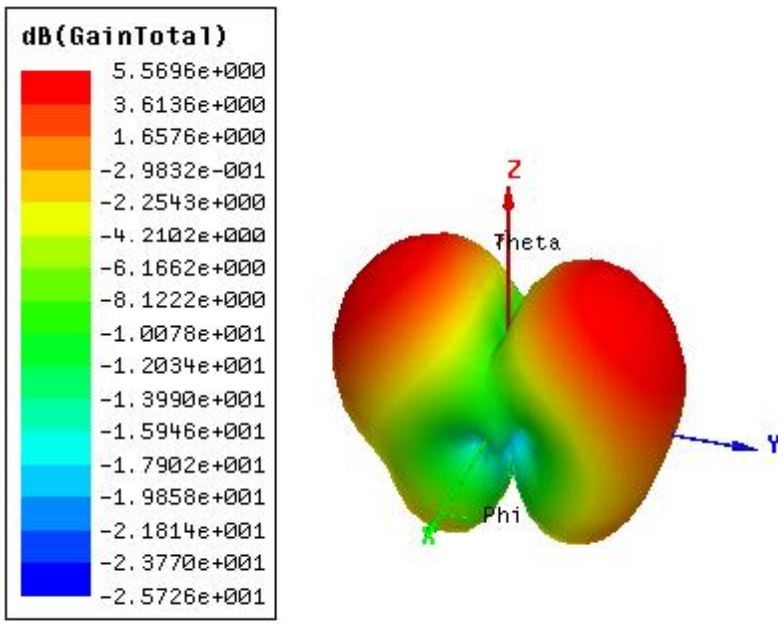

Figure 9: 3-D gain plot for $2^{\text {nd }}$ iteration of proposed fractal antenna at $6.57 \mathrm{GHz}$ frequency 


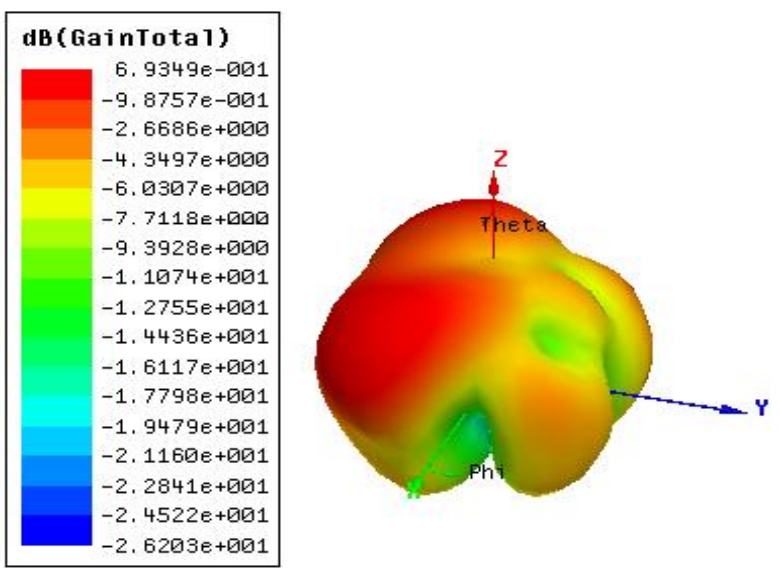

Figure 10: 3-D gain plot for $2^{\text {nd }}$ iteration of proposed fractal antenna at $7.99 \mathrm{GHz}$ frequency

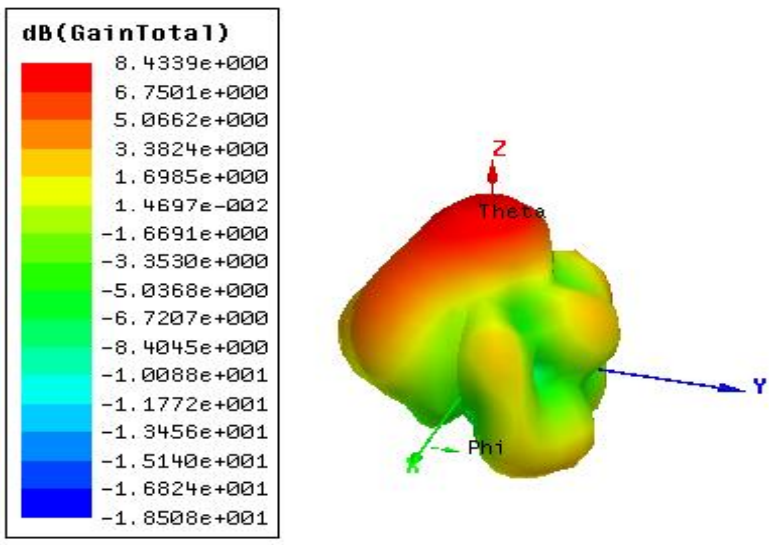

Figure 11: 3-D gain plot for $2^{\text {nd }}$ iteration of proposed fractal antenna at $9.69 \mathrm{GHz}$ frequency

Table 1. Simulated results of $0^{\text {th }}, 1^{\text {st }}$ and $2^{\text {nd }}$ iteration of proposed fractal antenna

\begin{tabular}{|c|c|c|c|}
\hline $\begin{array}{c}\text { Iteration } \\
\text { No. }\end{array}$ & $\begin{array}{c}\text { Resonant } \\
\text { frequencies } \\
\text { in GHz }\end{array}$ & $\begin{array}{c}\text { Return Loss } \\
\text { in dB }\end{array}$ & Gain in dB \\
\hline \multirow{3}{*}{$0^{\text {th }}$} & 3.14 & -25.77 & 2.53 \\
\cline { 2 - 4 } iteration & 4.85 & -13.85 & 1.39 \\
\cline { 2 - 4 } & 8.25 & -10.74 & 2.02 \\
\cline { 2 - 4 } & 9.27 & -17.18 & 1.01 \\
\hline \multirow{3}{*}{$1^{\text {st }}$} & 3.29 & -31.36 & 5.44 \\
\cline { 2 - 4 } iteration & 4.62 & -22.14 & -2.71 \\
\cline { 2 - 4 } & 8.04 & -12.14 & 3.50 \\
\cline { 2 - 4 } & 9.51 & -17.28 & 7.11 \\
\hline \multirow{4}{*}{$2^{\text {nd }}$} & 3.35 & -32.58 & 2.35 \\
\cline { 2 - 4 } iteration $^{*}$ & 4.50 & -15.04 & -1.27 \\
\cline { 2 - 4 } & 6.57 & -10.01 & 5.56 \\
\cline { 2 - 4 } & 7.99 & -17.48 & 6.93 \\
\hline & 9.69 & -22.95 & 8.43 \\
\hline
\end{tabular}

\section{CONCLUSIONS}

The paper presents the design of E-shaped fractal antenna in which three iterations has been designed and the different simulated results are observed and analyzed. The value of return loss and gain are compared in Table 1 and it shows that on increasing iteration number the value of return loss becomes more negative and the value of gain increases which is the desired condition for the antenna to work efficiently. The $2^{\text {nd }}$ iteration of proposed antenna works on five different frequencies but only four frequency bands are used for practical application because the gain at these frequencies are positive. So these frequency bands are used for different wireless applications.

\section{REFERENCES}

[1] A. Jamil, M. Z. Yusoff and N. Yahya, "Small Koch fractal antennas for wireless local area network", IEEE 978-1-4244-7006-8/10, pp. 104-108, 2010.

[2] A. Nagpal, S. S. Dhillon, "Multiband E-shaped Fractal Microstrip Patch Antenna with DGS for Wireless Applications.'IJETAE International Journal of Emerging Technology and Advance Engineering, Vol. 2, pp 241244.

[3] S. Yadav, R. Choudhary, U. Soni, A. Dadhich and M. M. Sharma, "Koch curve fractal antenna for Wi-Max and CBand wireless applications", IEEE $5^{\text {th }}$ International Conference- Confluence The Next Generation Information Technology Summit, pp. 490-494, 2014.

[4] C. A. Balanis, "Microstrip Antenna," Antenna Theory, Analysis and Design, Third Edition, John Wiley and Sons, pp. 811-876, 2010.

[5] R. Choudhary, S. Yadav, P. Jain and M. M. Sharma, "Full Composite Fractal Antenna with Dual Band used for Wireless Applications," International Conference on Advances in Computing, Communications and Informatics (ICACCI), pp. 2517-2520, 2014.

[6] N. Bayatmaku, P. Lotfi and M. Azarmanesh, "Design of Simple Multiband Patch Antenna for Mobile Communication Applications Using New E-shape Fractal."IEEE Antenna And Wireless Propagation Letters, vol .10,2011.

[7] S. Yadav, R. Choudhary, U. Soni, A. Dadhich and M. M. Sharma, "A Dual Band Star Fractal Antenna with Slot for Wireless Applications," International Conference on Signal Propagation and Computer Technology (ICSPCT), IEEE, pp. 738-740, 2014.

[8] J. S. Sivia and S. S. Bhatia, "Design of fractal based microstrip rectangular patch antenna for multiband applications," IEEE International Advance Computing Conference (IACC), pp. 712-715, 2015.

[9] G. Bharti, S. Bhatia and J. S. Sivia, "Analysis and design of triple band compact microstrip patch antenna with fractal elements for wireless applications," International Conference on Computational Modeling and Security (CMS 2016), Elsevier Procedia Computer Science, Vol. 85, pp. 380-385, 2016.

[10] A. Kaur and N. Sharma , "A quad band circular patch antenna with fractal elements for S-band and C-band applications," International Journal of Computer Applications, Vol. 144, No. 3, pp. 1-4, 2016. 